RESEARCH PAPER RP956

Part of Journal of Research of the National Bureau of Standards, Volume 17, December 1936

\title{
SELECTION OF COLORS FOR SIGNAL LIGHTS ${ }^{1}$
}

\author{
By Harry J. McNicholas ${ }^{2}$
}

\begin{abstract}
Various colored lights produced by combinations of a tungsten-filament lamp and commercially available colored-glass light filters were tested for efficiency and accuracy of identification in each of two six-color signal systems consisting, respectively, of red, orange-yellow, white, green, blue, and purple lights, and of red, orange, yellow, white, green, and blue lights . The tests were made by 38 normal observers on an outdoor range of 950 feet, for different weather conditions and signal intensities. Comparison between the two systems under prescribed service conditions showed that the use of purple with adequate lamp intensity is preferable to the use of both orange and yellow with red and white. Partial chromaticity tolerances and minimum lamp intensities have been determined for the six-color system containing purple.
\end{abstract}

\section{CONTENTS}

I. Stage

I. Statement of the problem

II. Apparatus and method

1. Light source and test range

2. Test method

III. Description of test colors and observers

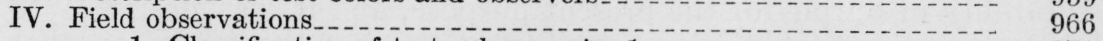

1. Classification of test colors, series 1.... 971

2. Classification of test colors, series $2 \ldots 974$

V. Effect of signal intensity on color discrimination

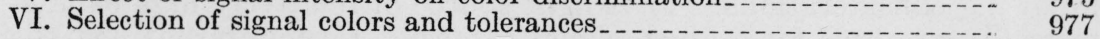

\section{STATEMENT OF THE PROBLEM}

The selection of colors for a system of signal lights is determined primarily by the number of colors required and the service conditions. Colors may be chosen with due consideration to some common defects in color vision, or for use only by normal observers. The lights may be seen as point sources or of sensible size; they may appear in association with other lights and on different backgrounds. Practical signal intensities and variable atmospheric conditions also enter into the choice of the colors. If but two or three colors constitute the system a wide range of service conditions may be met satisfactorily, and some preference for different possible colors accommodated; but as the number of colors required increases the choice becomes definitely restricted and the range of service conditions greatly reduced.

On American railroads suitable ranges of red, green, yellow, and sometimes white have been adopted for use by normal observers at

1 This work was undertaken at the request, and with the financial support, of the Bureau of Aeronautics of the U. S. Navy Department, and publication has been approved by that Bureau.

${ }_{2}$ The author is greatly indebted to various staff members of the National Bureau of Standards and the Bureau of Aeronautics for their cooperation in the recording and reduction of the field observations. In particular, the advice and contributions of F. C. Breckenridge and R. S. Hunter are acknowledged and appreciation is extended to C. G. Malmberg for help in the preparation of this publication. 
moderate signal intensities for long-distance work. For short distances additional signals are obtained by use of low-intensity blue and purple. The different colors of this system are thus of unequal importance and all six need not be mutually distinguishable under every condition of service. These circumstances determine to some degree what specific ranges of each color class may be employed for highest signal efficiency. Similarly, in the use of red, yellow, and green for street traffic control, the bluish-green glass selected is conditioned chiefly by the desirability of accommodating a fairly common abnormality in color vision (red-green deficiency).

The present investigation was undertaken to determine the best colors and their tolerances for a six-color signal system to be used at night, over distances up to approximately 1,500 feet. All colors enter the system on equal terms and positive identification of each color is required by normal observers, without benefit of simultaneous conirast with one or more of the other five, and under atmospheric conditions varying from clear to light haze. The choice of colors is limited, furthermore, by practical considerations, to that range obtainable by combinations of an incandescent lamp, operating at a fixed color temperature, with commercially available and reproducible coloredglass light filters, in the form of globular or tubular cover glasses for the bare lamps. The signals must be identified when seen as point sources of moderate or low intensity, which may approach under most adverse conditions the limit of chromatic visibility for normal observers.

The most obvious selection of colors includes suitable ranges of red, yellow, white, green, blue, and purple. At the beginning of this investigation there was considerable uncertainty, however, as to the suitability of purple for the present purpose, and it was desirable to investigate thoroughly the possibility of the substitution of another color in its place. The objection to the purple signal arises from the following considerations: (1) A light source of relatively high candlepower is required for a given signal intensity to counterbalance the high absorption of light in all suitable purple glasses; (2) its identification as a point source depends almost entirely on the recognition of a dichromatic red-blue hue pattern which varies markedly from one observer to another; (3) it is susceptible to change toward the red by excess scattering of the blue component in hazy atmosphere.

The two most likely possibilities for the elimination of purple are (1) the insertion of orange and yellow between red and white, and (2) the use of a blue-green and yellow-green between blue and yellowishwhite. It will be shown, however, that the latter suggestion is not feasible, so that the final choice is reduced to only two six-color sets of signal lights which will be denoted herein as sets $P$ and $O$ (purple and orange), respectively. Set $P$ consists of suitable ranges of red, orange-yellow, white, green, blue, and purple; set $O$ includes red, orange, yellow, white, green, and blue.

The specific purposes of the present investigation have been (1) to determine the maximum permissible chromaticity ranges for each color in the two six-color sets, (2) to indicate approximately the minimum lamp intensities (candlepowers) required for positive identification of each signal color, and (3) to make a direct comparison of the accuracy of identification of colors in the two signal systems. It is beyond the scope of the present paper to translate the selected chro- 
maticity ranges and minimum signal intensities into corresponding tolerances in the transmissive properties of various light filters and in the color temperature and candlepower of the incandescent lamps. Inasmuch as only commercially available colored-glass filters were used in this investigation, the translation will always be possible for the establishment of practical purchase specifications for the lamps and colored glassware.

\section{APPARATUS AND METHOD}

\section{LIGHT SOURCE AND TEST RANGE}

For the production of suitable colored-light signals, apparatus is required by which the lamp-and-filter combination may be conveniently varied by successive interchange of different filters, and the signal or source intensity adjusted in each case to a prescribed value. The arrangement used is shown in figure 1. A 400-watt lamp was

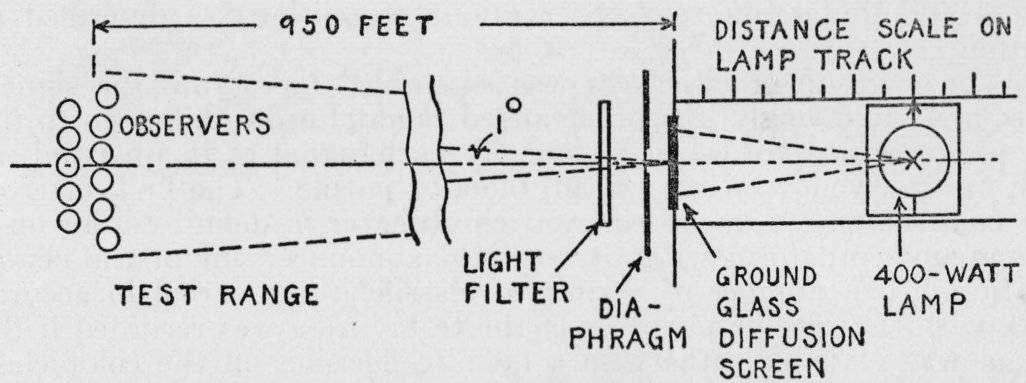

Figure 1.-Diagram of apparatus for the production of light signals.

operated at a color temperature of $2,840^{\circ} \mathrm{K}$ and mounted so that the distance from the plane of its filaments to the illuminated surface of a ground-glass diffusion screen could be varied at will. The diffusion screen was a plate of colorless borosilicate-crown glass, fine-ground on both sides, which served effectively as the source of light as seen by a group of observers stationed approximately 950 feet from the screen. The observers were grouped closely about the line of motion of the lamp filaments and subtended a horizontal plane angle of less than $1^{\circ}$ at the source. The area of the diffusion-screen source was limited by one of a set of diaphragms with circular apertures ranging from 3 to $30 \mathrm{~mm}$ in diameter. Any one of these apertures could be centered in the line of sight of the observers and was placed close to the transmitting surface of the diffusion screen. Various filters could be inserted successively between the observers and the diaphragm.

The color of the signal was changed by the insertion of different filters; the signal intensity was controlled by proper choice of the diaphragm and the position of the lamp on the track. By means of an illuminometer mounted at a distance of $50 \mathrm{~cm}$ from the diffusion screen, with its test plate centered in the observers' line of sight, the candlepower of the source (without filter) was determined for the various diaphragms and lamp positions. Since the luminous transmission of each filter used was known, the proper diaphragm and lamp position could be chosen for each filter so that all signals could be shown at constant intensity if desired. 
The test range extended from the flat roof of one building to that of another, both located on the grounds of the National Bureau of Standards. The apparatus described above was enclosed in a small roofhouse and the signals were exhibited through a diaphragmed hole in its wall. All observations were made in the early evening after dark. Observers were seated comfortably in the open and shielded from extraneous city lights. The signals appeared just below the horizon on a dark background of woodland and southern sky. Each observer was supplied with a board for support of his record paper. A lowintensity lamp with push-button switch was mounted conveniently on each board and could be lighted when needed for recording observations. Continuous telephonic communication was maintained between the observers and operators at the signal-sending station.

\section{TEST METHOD}

The field observations were necessarily divided into a number of separate test runs, each run being made with a selected set of test colors and under different observational conditions as described in section III.

When a group of observers was assembled for a run, the signals were presented singly in a prearranged random order unknown to the observers, who were asked to identify each signal as it appeared, as red, orange, yellow, white, green, blue, or purple. The first letter of the color name was recorded by each observer in definite order on a prepared record form without any oral announcement of the classification. The number of permitted classifications varied in accordance with the specific purposes of the test. An $x$ was recorded if the signal was invisible; otherwise a definite decision on the color class was required. In some runs all colors were exhibited at the same signal intensity (series 1, table 3); in other runs two or three fixed source intensities were used with each filter (series 2 , tables 4 and 5). In any run all different signals and all intensities of the same signal always appeared in random order. The complete single exhibition of all colors at all selected signal intensities was repeated many times, each time with a different random order of presentation, until each color had been shown a prescribed number of times, which varied from 2 to 15 in different runs.

The entire run was sometimes repeated under different weather conditions, signal intensities, or observer groups. Each signal lasted approximately 5 seconds, with about the same dark interval between the signals, during which the observers recorded their classification. Rest periods were provided as required.

Two operators were engaged in the presentation of the signals, one to interchange the filters and diaphragms, and the other to set the lamp in proper position and to supervise the course of the experiment in accordance with à master schedule of operations prearranged for the run. This schedule contained the actual order of presentation and prescribed intensities for the signals. The run was started, stopped, or irregularities corrected by telephonic communication between the operators and one observer, who was in charge of the test. After completion of the run the master schedule was compared with the record form of each observer and the individual color classifications were rearranged in definite order with respect to the test colors presented, the permitted classifications, and the source or signal intensities. 


\section{DESCRIPTION OF TEST COLORS AND OBSERVERS}

A description of the signal colors as actually perceived is complieated by many complex factors. It is known that the perception of colors and the discrimination between them varies with the intensity and area of retinal illumination, and these factors become of considerable importance as the observational conditions approach the threshold of chromatic visibility for the very small sources with which we are herein concerned. Aberrations in the lens system of the eye also play an important role in the appearance and identification of the signals. For the average observer the greens, blues, and purples appear to spread over the field of view to a far greater extent than do the reds or yellows. The differential effect may be appreciable even between the adjacent red, orange, and yellow signals so that the apparent sizes of the "point" sources is of some assistance in the discrimination between them.

Purple filters transmit only the ends (red and blue) of the visible spectrum. For the majority of observers the identification of purple depends largely on the effect of chromatic aberration in the eye, resulting in a partial or complete spatial resolution of the purple into its red and blue components. Most normal observers see the purple source as a distinct red center surrounded by a diffuse blue halo or blue radial streamers. Some observers see this color pattern reversed. Others see the blue spread with the red concentrated along a horizontal line. Various other patterns and degrees of spatial resolution are observed, including cases wherein the dichromatic effect is indistinct so that the signal appears as nearly a true monochromatic purple spread. This partial resolution of a point source into chromatic components is also noted by a few observers for signal white. A poorly defined orange-yellow center may be seen surrounded by a greenishblue spread. Such sources, at medium intensities, have been mistaken occasionally for green or purple in these tests.

The phenomena described all enter into the experimental selection of the signal lights, and complicate their precise description or specification. Little work has been done on the colorimetry of point sources, and established colorimetric methods are all referred to simplified conditions of observation which include retinal illuminations of 100 photons or above, with field sizes of $2^{\circ}$ or more. Under these conditions the aberration effects are absent, large variations in intensity are of reduced importance, and definite experimental relations are established for purposes of practical colorimetry. In general, the principal requirements of the present investigation are adequately served by a numerical description of the test colors as they would appear to a standardized normal observer under the observational and reference conditions as defined for colorimetric purposes by the International Commission on Illumination. ${ }^{3}$ It will be of interest, however, in the following discussion, to indicate qualitatively some changes in color perception accompanying the transition from standard conditions of observation to service conditions. In particular, an additional specification for purples will be provided to accommodate the aberration effect. Knowing the absolute intensity and color temperature of the source, and the spectral transmission

\footnotetext{
3 Proc. 8th Session, International Commission on Illumination, Cambridge, p. 19-29 (September 1931). T. Smith and J. Guild, The CIE colorimetric standards and their use, Trans. Opt. Soc. 33, 73 (1931-32). D. B. Judd, The 1931 ICI standard observer and coordinate system for colorimetry, ,J. Opt. Soc. Am. 23,359 (1933).
} 
of the filters used, we may proceed then for the standard conditions by purely analytical and graphical methods to separate evaluations of the luminous and chromatic aspects of the signal colors, with reference to the ICI standard observer and specified coordinate systems. ${ }^{4}$

The absolute intensity of the diffusion-screen source (without filter) and its color temperature were determined by direct comparison with laboratory standards. The spectral transmission of each filter used in this investigation was measured with the Koenig-Martens spectrophotometer, ${ }^{5}$ and luminous transmissions ${ }^{6}$ were computed for the standard observer and source at $2,840^{\circ} \mathrm{K}$. The values are recorded in column 3 of table 1 , following the NBS laboratory number and manufacturer's designation of the filter in columns 1 and 2 , respectively. These NBS filter numbers are also used throughout this paper to denote the corresponding signal color. Signal intensity is the product of source intensity by the luminous transmission of the filter used, and serves in the present investigation as the quantitative expression for the luminosity of the signal color, as distinct from the color quality, or chromaticity.

The chromaticity ${ }^{7}$ of each signal color is herein evaluated with reference to two different trilinear coordinate systems. The $(x, y, z)$ coordinates in columns 4,5 , and 6 of table 1 , refer to the standard ICI system of colorimetry. The $(r, g, b)$ coordinates in columns 7,8 , and 9 refer to the UCS (uniform chromaticity scale) system more recently devised by Judd. ${ }^{8}$ Values on the UCS system are graphically represented for all the test colors on the equilateral triangle of figure 2. Inasmuch as the three coordinates sum to unity, by definition, only two of them need be labeled in the figure. This is done for $r$ and $g$ and the unused parts of the triangle are eliminated. For comparison and reference on the same diagram the locus of the pure spectrum colors is also shown, with the limiting purple line connecting the extreme spectral red and blue (violet). All real colors lie within this enclosure. Highly saturated colors are near the boundary and from thence the colors decrease progressively in saturation in the general direction of white.

The characteristic property of the UCS diagram, which is of particular utility in the present connection, is that any series of colors equally separated in chromaticity will be represented on this diagram as approximately equidistant from one another. Hence, if concentric circles be drawn in any region of the diagram all colors on the circumference of any one circle differ in chromaticity from the central color by approximately the same amount.

\footnotetext{
4 For the theory of the transformation from one coordinate system to another, see D. B. Judd, Reduction of data on mixture of color stimuli, BS J. Research 4, 515 (1930) RP163; J. Guild, On the fixed points of a colorimetric system, Trans. Opt. Soc. 32, 25 (1930-31).

$\checkmark$ H. J. McNicholas, Equipment for routine spectral transmission and reflection measurements, BSJ. Research 1, 793 (1928). RP 30.

6 Luminous transmission is the ratio of the candlepower of the source-filter combination to the candle power of the source alone, as would be measured by the standard observer with the source in operation at a color temperature of $2,840^{\circ} \mathrm{K}$.

7 The term chromaticity characterizes the quality of the color, as distinct from its purely luminous aspect, and is perhaps most readily visualized in terms of hue and saturation. See Report of Committee on Colorimetry for 1920-21, J. Opt. Soc. Am. \&Rev. Sci. Instr. 6,527 (1922). Hue is that attribute of chromaticity which classifies all colors in their departure from gray (or white) as reddish, yellowish, greenish, etc. Saturation is that attribute of all colors possessing a hue, which determines their degree of departure from gray (or white). Gray (or white) is hueless and completely unsaturated; homogeneous spectrum colors possess the maximum saturation possible for a given hue. It will be convenient to refer qualitatively to the hue and saturation of the signal colors, in relation to their quantitative expression and graphical representation in trilinear coordinates.

8 D. B. Judd, A Maxwell triangle yielding uniform chromaticity scales, J. Research NBS 14, 41 (1935) RP756 or J. Opt. Soc. Am. 25, 24 (1935).
} 
An outstanding feature of the diagram is the proximity of the whites to the spectrum locus. Under the observational conditions of the present investigation color 8472 is found roughly to define the center of the best range of signal white. Drawing a circle with this center and tangent to the spectrum locus shows that wave lengths in the neighborhood of $\lambda 572$ are nearest in chromaticity to the signal white, and hence the least saturated of all spectrum colors. The same wave length is found by Guild ${ }^{9}$ as that most easily confused with subjective white, for small sources and five observers. Again, it has been shown by others ${ }^{10}$ for standard field sizes that wave lengths in

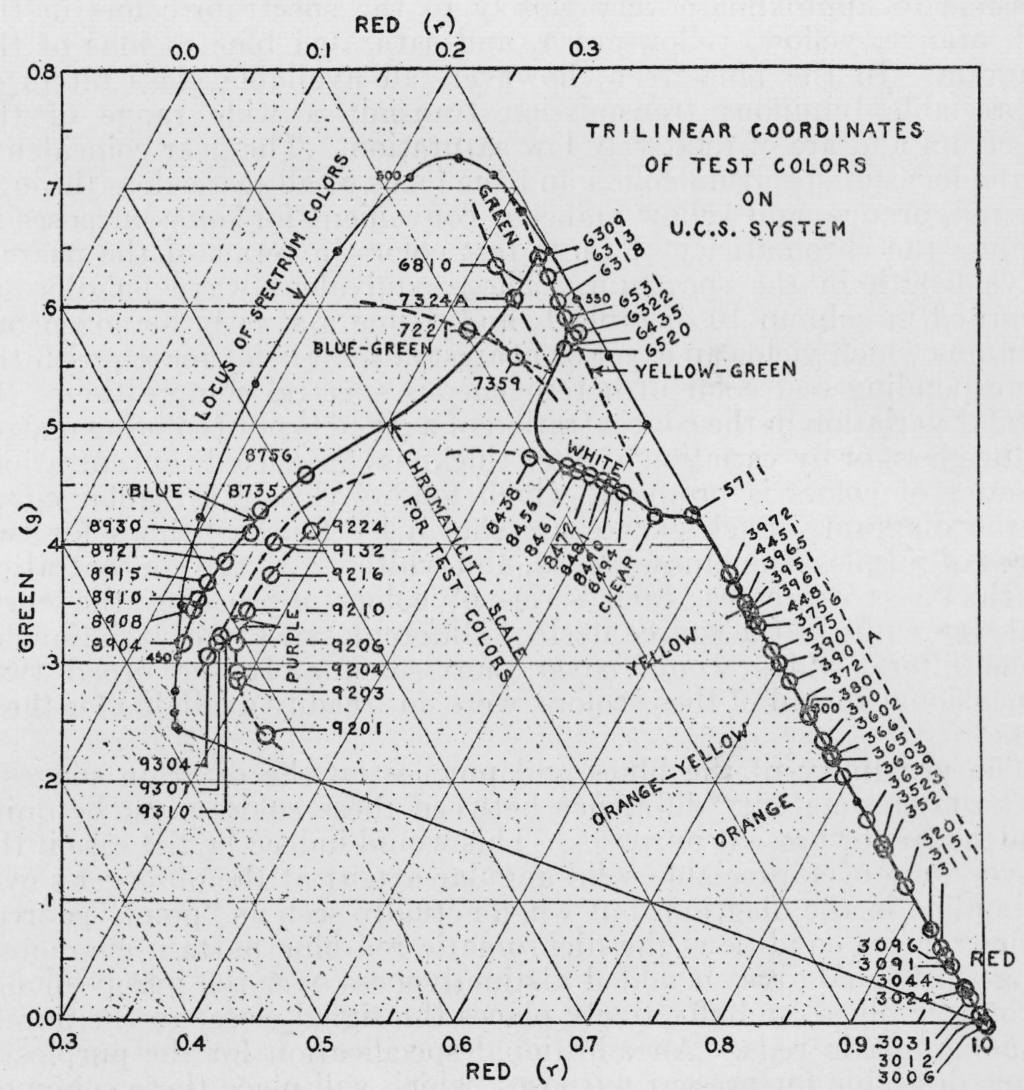

FIgURE 2.-Trilinear coordinates of test colors.

the range between 570 and 572 represent the spectral region of lowest saturation. In the choice of two or three signal colors between green and red the hueless and completely achromatic nature of white gives it a unique advantage over the nearby weak yellows. The identification of this signal is based solely on the observer's subjective concep-

${ }^{9} \mathrm{~J}$. Guild, On the selection of a suitable yellow glass for railway signals, Proc. Int. Cong. Illum., Saranac Inn, New York, p. 862-876 (September 1928).

${ }_{10}$ I. G. Priest and F. G. Brickwedde, The minimum perceptible colorimetric purity as a function of dominant wave length with sunlight as neutral standard, J. Opt. Soc. Am. \& Rev. Sci Instr. 13, 306 (1926). D. McL. Purdy, On the saturations and chromatic thresholds of the spectral colors, Brit. J. Psychol. (Gen. Sec.) 21 (part 3), 283 (1931). I. C. Martin, F. L. Warburton, and W. J. Morgan, Determination of the sensitiveness of the eye to differences in the saturation of colours, Medical Research Council, Reports of the Committee upon the Physiology of Vision, XIII, Special Report Series, no. 188, London (1933). 
tion of whiteness. It is apparent that little or no advantage would be gained by use of a weak yellow in place of white in a six-color signal system.

It is well known that sensibility to hue differences is greater for colors of high saturation. Hence, for maximum distinctiveness from one another and from white, the chromatic colors should lie as close as possible to the spectrum locus and, in so far as the given UCS diagram applies to colors of "point" sources, the best choice of colors would be that which separates them equally on this diagram.

By use of only commercially available colored-glass filters it is possible to approximate very closely to the spectrum colors in the red, orange, yellow, yellow-green, and saturated blue regions of the diagram. In the blue-green, however, all available glass filters of appreciable luminous transmission transmit a wide range of the spectrum and are of relatively low saturation. The near coincidence of the locus of spectrum colors and the locus of all test colors through the red, orange, and yellow makes it convenient for some purposes to express the chromaticity of these test colors in terms of the nearest wave length in the spectrum. These equivalent wave lengths are recorded in column 10 of table 1 , and define a strictly homogeneous stimulus which yields an exact or nearest chromaticity match with the corresponding test color of heterogeneous spectral composition. By regular variation in the concentration of a given type of coloring matter in the glass, or by variation of filter thickness for a fixed concentration, a series of colors is produced which follows closely a regular curve in the diagram. Such curves are shown by the dash lines for two types of purples, the blues, greens, and whites. As the concentration or thickness decreases, each series of colors approaches the chromaticity value of the source itself. Different types and variations of green filters, which would cover more adequately the broad twodimensional spread of these colors, were not readily available for these tests.

The proximity of the blues and purples on the diagram suggests that the chromaticity difference between these colors must be quite inadequate for present purposes. This would indeed be the case if the source were of appreciable solid angular extent at the observer's eye, as implied in the diagram; but when actually seen as "point" sources under service conditions the dichromatic red-blue pattern characterizing this signal gives it added distinctiveness over the purely monochromatic blues, and effectively places the signal closer to the purely monochromatic reds. An additional specification for the purples is hence desirable for present purposes, which will place these colors on a linear scale extending between the extreme blue and red. The required parameter is satisfactorily provided by the ratio of the redlight transmission $\left(T_{r}\right)$ to the entire luminous transmission $\left(T_{w}\right)$. The values of this ratio are given in the lower part of column 10, table 1, and the relation to $T_{w 0}$ shown in figure 3, for the two types of purpleglass filters employed in this investigation. 
TABLE 1.-Description of test colors

\begin{tabular}{|c|c|c|c|c|c|c|c|c|c|}
\hline \multirow{4}{*}{$\begin{array}{l}\text { NBS num- } \\
\text { ber of filters }\end{array}$} & \multirow{4}{*}{ Maker's designation of filters } & \multicolumn{8}{|c|}{$\begin{array}{l}\text { Colorimetric properties of source-filter combinations referred } \\
\text { to the } 1931 \text { ICI standard observer and source at } 2,840^{\circ} \mathrm{K}\end{array}$} \\
\hline & & \multirow{3}{*}{$\begin{array}{c}\text { Lumi- } \\
\text { nous } \\
\text { trans- } \\
\text { mis- } \\
\text { sion } \\
T_{*}\end{array}$} & \multicolumn{6}{|c|}{ Trilinear coordinates } & \multirow{3}{*}{$\begin{array}{l}\text { Wave } \\
\text { length } \\
\text { for } \\
\text { reds } \\
\text { and } \\
\text { yel- } \\
\text { lows } \\
\lambda\end{array}$} \\
\hline & & & \multicolumn{3}{|c|}{ ICI system (standard) } & \multicolumn{3}{|c|}{ UCS system (Judd) } & \\
\hline & & & $x$ & $y$ & 2 & $r$ & $\theta$ & $b$ & \\
\hline 1 & 2 & 3 & 4 & 5 & 6 & 7 & 8 & 9 & 10 \\
\hline $\begin{array}{l}3006 \ldots- \\
3012 \ldots\end{array}$ & $\begin{array}{l}\text { Jena RG8 } \\
\text { Corn. } 241,17.5 \% \\
\text { Corn. 241, } 46 \% \\
\text { Corn. } 241,34.5 \% \\
\text { Corn. } 241,68 \% \\
\text { Corn. } 243,126 \% \\
\text { Kopp R. R. Red. }\end{array}$ & $\begin{array}{l}0.0006 \\
.0095 \\
.025 \\
.020 \\
.036 \\
.074 \\
.069\end{array}$ & $\begin{array}{r}0.7363 \\
.7326 \\
.7281 \\
.7258 \\
.7252 \\
.7193 \\
.7164\end{array}$ & $\begin{array}{l}0.2637 \\
.2674 \\
.2718 \\
.2742 \\
.2748 \\
.2807 \\
.2836\end{array}$ & $\begin{array}{l}0.0000 \\
.0000 \\
.0000 \\
.0000 \\
.0000 \\
.0000 \\
.0000\end{array}$ & $\begin{array}{l}1.0000 \\
.9933 \\
.9795 \\
.9722 \\
.9704 \\
.9529 \\
.9444\end{array}$ & $\begin{array}{l}0.0000 \\
.0067 \\
.0205 \\
.0278 \\
.0296 \\
.0471 \\
.0556\end{array}$ & $\begin{array}{l}0.0000 \\
.0000 \\
.0000 \\
.0000 \\
.0000 \\
.0000 \\
.0000\end{array}$ & $\begin{array}{l}700 \\
690 \\
655\end{array}$ \\
\hline 111 & $\begin{array}{l}\text { Corn. } 243,165 \% \\
\text { Corn. } 243,218 \%- \\
\text { Corn. 246, 78\% } \\
\text { Corn. } 246,104 \%- \\
\text { Corn. } 246,100 \%-\end{array}$ & $\begin{array}{l}.095 \\
.127 \\
.177 \\
.226 \\
.217\end{array}$ & $\begin{array}{l}.7143 \\
.7088 \\
.6953 \\
.6829 \\
.6812\end{array}$ & $\begin{array}{l}.2857 \\
.2913 \\
.3046 \\
.3169 \\
.3186\end{array}$ & & & & & \\
\hline $\begin{array}{l}3639 \\
3603 \\
3651 \\
3601\end{array}$ & $\begin{array}{l}\text { Corn. 246, } 123 \% \\
\text { Corn. 246, 142\% } \\
\text { Corn. 348, 155\% } \\
\text { Corn. 348 } \\
\text { Corn. 246 }\end{array}$ & $\begin{array}{l}.266 \\
.326 \\
.340 \\
.338 \\
.341 \\
.364\end{array}$ & $\begin{array}{l}.6720 \\
.6561 \\
.6485 \\
.6476 \\
.6471 \\
.6411\end{array}$ & $\begin{array}{l}.3278 \\
.3436 \\
.3512 \\
.3521 \\
.3526 \\
.3585\end{array}$ & & & $\begin{array}{l}.1691 \\
.2039 \\
.2196 \\
.2214 \\
.2224 \\
.2343\end{array}$ & & \\
\hline 3801-..- & $\begin{array}{l}\text { Jena } O G 2 \\
\text { Corn. } 350, Y 6.3 \\
\text { NBS }(3901+3756) \\
\text { Corn. Y5 } \\
\text { Corn. 349, Y5 }\end{array}$ & $\begin{array}{l}.452 \\
.427 \\
.354 \\
.463 \\
.540\end{array}$ & $\begin{array}{l}.6304 \\
.6297 \\
.6137 \\
.6059 \\
.5984\end{array}$ & $\begin{array}{l}.3693 \\
.3699 \\
.3858 \\
.3935 \\
.4009\end{array}$ & & & & & \\
\hline 3972 & $\begin{array}{l}\text { Corn. 350, Y3.5 } \\
\text { Corn. 330 } \\
\text { Corn. 350, Y3.0 } \\
\text { Corn. Y3.0 } \\
\text { Corn. 350, Y2.8 } \\
\text { Corn. 3301, Y2.1. } \\
\text { Corn. 351, } \\
\text { Jena G.G.11. }\end{array}$ & $\begin{array}{l}.555 \\
.370 \\
.612 \\
.592 \\
.651 \\
.488 \\
.725 \\
.873\end{array}$ & $\begin{array}{l}.5852 \\
.5801 \\
.5776 \\
.5755 \\
.5724 \\
.5583 \\
.5541 \\
.5065\end{array}$ & $\begin{array}{l}.4138 \\
.4151 \\
.4212 \\
.4233 \\
.4262 \\
.4295 \\
.4436 \\
.4723\end{array}$ & & & $\begin{array}{l}.3312 \\
.3361 \\
.3426 \\
.3457 \\
.3503 \\
.3625 \\
.3755 \\
.4246\end{array}$ & & \\
\hline & $\begin{array}{l}\text { (Colorless glass) Source 2,8 } \\
\text { Corn. 557, 284\% } \\
\text { Corn. 557, 247\% } \\
\text { Corn. 557, 216\% } \\
\text { Corn. 557, } 190 \% \\
\text { Corn. 557, 160\% } \\
\text { Corn. 557, 148\% } \\
\text { Corn. 557, 99\% }\end{array}$ & $\begin{array}{l}.920 \\
.567 \\
.490 \\
.429 \\
.376 \\
.320 \\
.294 \\
.199\end{array}$ & $\begin{array}{l}.4476 \\
.4030 \\
.3881 \\
.3750 \\
.3601 \\
.3446 \\
.3330 \\
.2921\end{array}$ & $\begin{array}{l}.4075 \\
.3907 \\
.3829 \\
.3750 \\
.3649 \\
.3527 \\
.3472 \\
.3078\end{array}$ & & $\begin{array}{l}.5434 \\
.5086 \\
.4973 \\
.4874 \\
.4762 \\
.4647 \\
.4549 \\
.4227\end{array}$ & $\begin{array}{l}.4239 \\
.4441 \\
.4496 \\
.4540 \\
.4584 \\
.4621 \\
.4672 \\
.4734\end{array}$ & $\begin{array}{l}.0327 \\
.0474 \\
.0531 \\
.0586 \\
.0653 \\
.0732 \\
.0779 \\
.1039\end{array}$ & \\
\hline & $\begin{array}{l}\text { Corn. } 440,206 \% \\
\text { Kopp } G X \\
\text { Corn. } 401 \\
\text { Corn. } 401,93 \% \\
\text { Jena } V G 2 \\
\text { Corn. } 401,71 \% \\
\text { Corn. } 401 \\
\text { Corn. } 401,37 \% \\
\text { Kopp } G . B \\
\text { Corn. } 440+\mathrm{NBS} 4306 \\
\text { Corn. } 440,80 \%\end{array}$ & $\begin{array}{l}.269 \\
.098 \\
.200 \\
.117 \\
.161 \\
.093 \\
.067 \\
.049 \\
.045 \\
.082 \\
.109\end{array}$ & $\begin{array}{l}.2458 \\
.3018 \\
.3098 \\
.3182 \\
.2906 \\
.2742 \\
.2446 \\
.2202 \\
.1721 \\
.2136 \\
.1855\end{array}$ & $\begin{array}{l}.4152 \\
.5288 \\
.5734 \\
.6020 \\
.5996 \\
.6259 \\
.6643 \\
.6929 \\
.5442 \\
.5184 \\
.3755\end{array}$ & $\begin{array}{l}.3390 \\
.1693 \\
.1168 \\
.0798 \\
.1098 \\
.0999 \\
.0908 \\
.0869 \\
.2837 \\
.2680 \\
.4390\end{array}$ & $\begin{array}{l}.3706 \\
.4039 \\
.4054 \\
.4085 \\
.3911 \\
.3795 \\
.3609 \\
.3468 \\
.3171 \\
.3442 \\
.3220\end{array}$ & $\begin{array}{l}.5578 \\
.5655 \\
.5747 \\
.5779 \\
.5909 \\
.6046 \\
.6255 \\
.6406 \\
.6340 \\
.6076 \\
.5805\end{array}$ & $\begin{array}{l}.0716 \\
.0308 \\
.0199 \\
.0136 \\
.0180 \\
.0158 \\
.0137 \\
.0126 \\
.0489 \\
.0482 \\
.0975\end{array}$ & \\
\hline & $\begin{array}{l}\text { Corn. 556, } 126 \% \\
\text { Corn. 556, 79\% } \\
\text { Corn. 554 } \\
\text { Corn. 554, 36\% } \\
\text { Corn. 554, 24.8\% } \\
\text { Corn. 554, } 18.4 \% \\
\text { Corn. 554, } 14.4 \% \\
\text { Corn. 511, } 9.2 \%\end{array}$ & $\begin{array}{l}.034 \\
.021 \\
.016 \\
.011 \\
.0075 \\
.0056 \\
.0047 \\
.0028\end{array}$ & $\begin{array}{l}.1510 \\
.1439 \\
.1473 \\
.1464 \\
.1465 \\
.1483 \\
.1497 \\
.1550\end{array}$ & $\begin{array}{l}.1202 \\
.0846 \\
.0728 \\
.0550 \\
.0432 \\
.0360 \\
.0325 \\
.0224\end{array}$ & $\begin{array}{l}.7288 \\
.7715 \\
.7799 \\
.7986 \\
.8104 \\
.8157 \\
.8178 \\
.8226\end{array}$ & $\begin{array}{l}.2595 \\
.2391 \\
.2406 \\
.2327 \\
.2281 \\
.2282 \\
.2294 \\
.2351\end{array}$ & $\begin{array}{l}.4591 \\
.4293 \\
.4100 \\
.3865 \\
.3682 \\
.3534 \\
.3450 \\
.3172\end{array}$ & $\begin{array}{l}.2814 \\
.3316 \\
.3494 \\
.3808 \\
.4037 \\
.4184 \\
.4256 \\
.4476\end{array}$ & $\begin{array}{l}\frac{T_{r}}{T_{w}} \text { for } \\
\text { pur- } \\
\text { ples }\end{array}$ \\
\hline $\begin{array}{l}9132 \ldots- \\
9224-- \\
9307-- \\
9216-- \\
9310-- \\
9304-- \\
9210-- \\
9206-- \\
9204-- \\
9203-- \\
9201-- \\
3006-- \\
\end{array}$ & 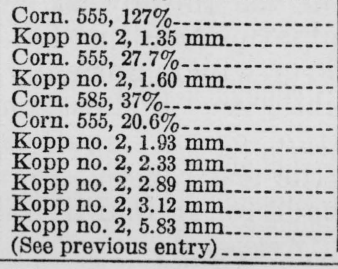 & $\begin{array}{l}.020 \\
.011 \\
.0039 \\
.0080 \\
.0049 \\
.0030 \\
.0053 \\
.0032 \\
.0019 \\
.0015 \\
.0004\end{array}$ & $\begin{array}{l}.1596 \\
.1718 \\
.1661 \\
.1683 \\
.1657 \\
.1666 \\
.1686 \\
.1731 \\
.1807 \\
.1830 \\
.2055\end{array}$ & $\begin{array}{l}.0796 \\
.1004 \\
.0325 \\
.0683 \\
.0348 \\
.0270 \\
.0494 \\
.0381 \\
.0322 \\
.0306 \\
.0275\end{array}$ & $\begin{array}{r}.7606 \\
.7278 \\
.8014 \\
.7633 \\
.7995 \\
.8064 \\
.7820 \\
.7887 \\
.7871 \\
.7863 \\
.7670 \\
\end{array}$ & $\begin{array}{r}.2626 \\
.2861 \\
.2606 \\
.2741 \\
.2605 \\
.2598 \\
.2701 \\
.2755 \\
.2887 \\
.2931 \\
.3381 \\
\end{array}$ & $\begin{array}{l}.4022 \\
.4125 \\
.3180 \\
.3745 \\
.3230 \\
.3054 \\
.3443 \\
.3171 \\
.2929 \\
.2857 \\
.2395 \\
. . . . . .\end{array}$ & $\begin{array}{r}.3352 \\
.3014 \\
.4214 \\
.3514 \\
.4165 \\
.4338 \\
.3856 \\
.4074 \\
.4183 \\
.4212 \\
.4224 \\
. . . . .\end{array}$ & $\begin{array}{r}.071 \\
.110 \\
.123 \\
.132 \\
.132 \\
.158 \\
.159 \\
.235 \\
.340 \\
.368 \\
.664 \\
1.000 \\
\end{array}$ \\
\hline
\end{tabular}

$106351-36-11$ 
In further reference to the change in the appearance and chromaticity of the signal lights, when compared under actual service conditions and under standard laboratory conditions, it was noted qualitatively (by memory comparison) during the course of this investigation that on the range the orange and orange-yellow signals appeared less saturated and slightly shifted in hue toward the yellow. Similarly, it was observed that the greens under service conditions decreased considerably in saturation and the normal hue difference between the greens and blues was considerably reduced. In this connection it may be noted also that the progressive spreading of the signals through the green and blue results in a corresponding progressive decrease in retinal illumination for these signals. Since this decrease would be greater for the shorter wave lengths it is possible that this aberration effect may result in a slight hue shift of the less saturated blues toward the green.

The combined effects of decreasing field size and retinal illumination on the saturation of the pure spectrum colors was investigated experi-

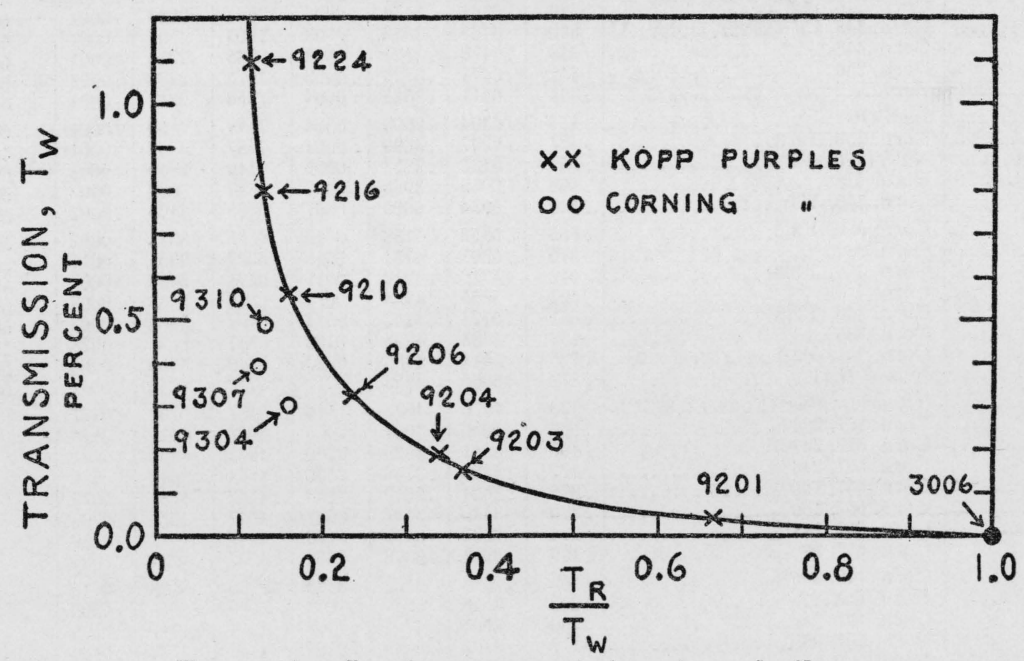

FIgURE 3.-Luminous transmission of purple filters.

mentally by Purdy. ${ }^{11}$ For such changes in observational conditions it was found that the color differences between the various parts of the spectrum were greatly reduced until the threshold of chromatic visibility was reached, below which all parts of the spectrum except the long-wave end appeared achromatic or gray. The long wave end changed with decreasing retinal illumination from strong to weak red, but at the threshold of chromatic visibility passed directly from weak red to complete invisibility. This region has the lowest chromatic threshold with respect to retinal illumination and is followed in increasing order of the threshold by parts which normally appear orange, yellow, and blue. Green exhibits the highest chromatic threshold, and in the present investigation green signals appeared greatly desaturated at low intensities on the test range. Some of the field observations to be described were made for retinal illuminations

${ }_{11} \mathrm{D} . \mathrm{McL}$. Purdy, On the saturation and chromatic thresholds of the spectral colours, Brit. J. Psychol. (Gen. Sec.) 21, 283 (1931). 
below and not far above the chromatic thresholds for the red, green, blue, and purple signals.

These considerations afford a qualitative explanation of the difficulties experienced in the discrimination between greens and blues in the present investigation, notwithstanding the wide separation of these colors on the diagram in figure 2 ; for, under service conditions, the actual chromaticity difference between these colors is considerably less than is indicated on the diagram. The situation may be expressed by saying that the locus of the spectrum colors on a uniform-chromaticity-scale diagram, established for actual service conditions, would show, relative to the given UCS diagram of figure 2, a slightly greater separation between the test colors throughout the orange and orange-yellow and a considerably decreased separation between the strong greens and blues. Accompanying this change there would be undoubtedly a general reduction in the total area included by the spectrum locus and the purple line. It will be evident from the observations to be described that it is impossible to interpose a distinctive "point" signal between the strong blue and the yellow-green signals. Another practical difficulty in this connection is involved in the im-

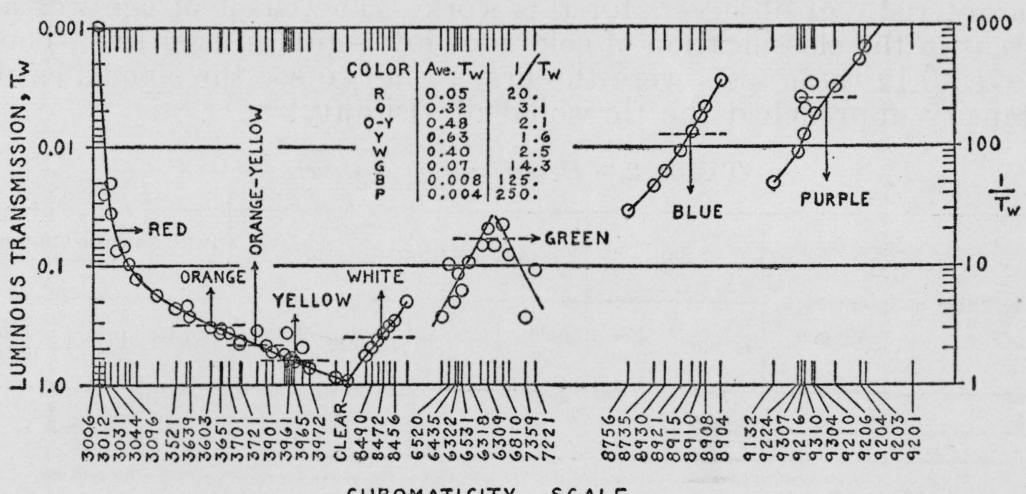

CHROMATICITY SCALE

FIGURE 4.-Luminous transmission of filters used in the production of light signals.

possibility of producing highly saturated blue-greens by use of commercial colored-glass filters of sufficient luminous transmission.

The heavy solid line on the $(r, g)$ diagram, passing through the entire ranges of the reds, yellows, whites, greens, and blues, is drawn to provide a linear chromaticity scale along which all the test colors may be arranged in a logical regular order, and the results of the field observations and other information readily presented in graphical form. The scale is laid out along the horizontal axes in figures 4 and 6 , with the spacing of all colors (except the purples) always proportional in each figure to their spacing (or projected spacing) along the curve in figure 2. At the extreme end of the blues (color 8904) the chromaticity scale is extended through the purples to the extreme red '(color 3006 ), with the spacing of colors now proportional to the square root of the $T_{r} / T_{w}$ ratio for these colors. This particular spacing for the purples is arbitrarily chosen wholly for convenience in the graphical representations.

Figure 4 shows the variation in luminous transmission of all filters used in the production of colors along the linear chromaticity scale. 
Transmissions are represented on a logarithmic scale. The right-hand ordinate scale indicates the relative source intensity required behind each filter for the production of constant signal intensities. Thus, if a 1-candlepower lamp suffices for the filter producing the white signal, about 50 and 100 candles are required, respectively, for the average blue and purple filters.

A total of 38 observers participated in the recording of the field observations. Their distribution with respect to sex, age, and other characteristics is shown in table 2. Not all observers were available for the color-blindness tests, but the field observations do not show any obvious or consistent abnormality between any of the observers in the classification of the test colors. All the observers may be regarded as of normal color vision in the ordinary sense of the word. Several observers had some previous experience in the matching of colors or discrimination between them, but the majority had no experience or special training in this respect. In the same test an observer with no experience whatever was sometimes more consistent and precise in the color classification than another with considerable experience. There is no evidence that experience is an important characteristic of observers for this work. The effect of age was apparent in the classification of colors for low signal intensities. Those above 40 in these tests were the first to fail to see the signals as the intensity approached the threshold of visibility.

TABLE 2.-Description of observers

\begin{tabular}{|c|c|c|c|c|c|c|c|c|c|}
\hline \multirow{2}{*}{ Number of observers } & \multicolumn{2}{|c|}{ Sex } & \multicolumn{4}{|c|}{ Age distribution (years) } & \multicolumn{3}{|c|}{$\begin{array}{l}\text { Ishihara color-blindness } \\
\text { test }\end{array}$} \\
\hline & Male & $\begin{array}{l}\mathrm{Fe}- \\
\text { male }\end{array}$ & $\begin{array}{c}\text { Below } \\
20\end{array}$ & 20 to 30 & 30 to 40 & $\underset{40}{\operatorname{Above}}$ & Passed & Failed & $\begin{array}{l}\text { Not } \\
\text { tested }\end{array}$ \\
\hline 38............ & 29 & 9 & 3 & 19 & 13 & 3 & 21 & 0 & 17 \\
\hline
\end{tabular}

\section{FIELD OBSERVATIONS}

In the assignment of a series of test colors to given color classes by a group of normal observers, chromaticity, or hue in particular, is in most cases the primary discrimination factor determining the classification. In the case of purples the dichromatic hue pattern becomes the dominant criterion for recognition. The differential spreading of the purple and the monochromatic signal lights is a minor influence in this respect. The subjective criterion of chromaticity is modified by the following secondary factors and test conditions, which are listed below in their estimated order of importance.

(1) The association, through color education and memory, of a given test color with all adjacent colors included in the test. The effect is a maximum when the test colors cover the entire chromaticity range between adjacent color classes; it is reduced to a minimum when the test colors define only the maximum permissible tolerances in the chromaticity ranges of the given color classes.

(2) The variation in individual color-vision characteristics and association tendencies within a group of normal observers.

(3) The range of signal intensities, or equivalent distances, over which the signal colors must be positively identified. 
(4) The weather conditions affecting atmospheric transmission or luminous contrasts in the field of view.

A systematic survey of the separate effects of each factor on the color classifications was impractical under the circumstances of the present investigation. Simultaneous uncontrolled variations in conditions occurred in such manner as often to prevent the true effect being derived from the observations. Such information as may be gleaned from the whole body of data will appear throughout the discussion.

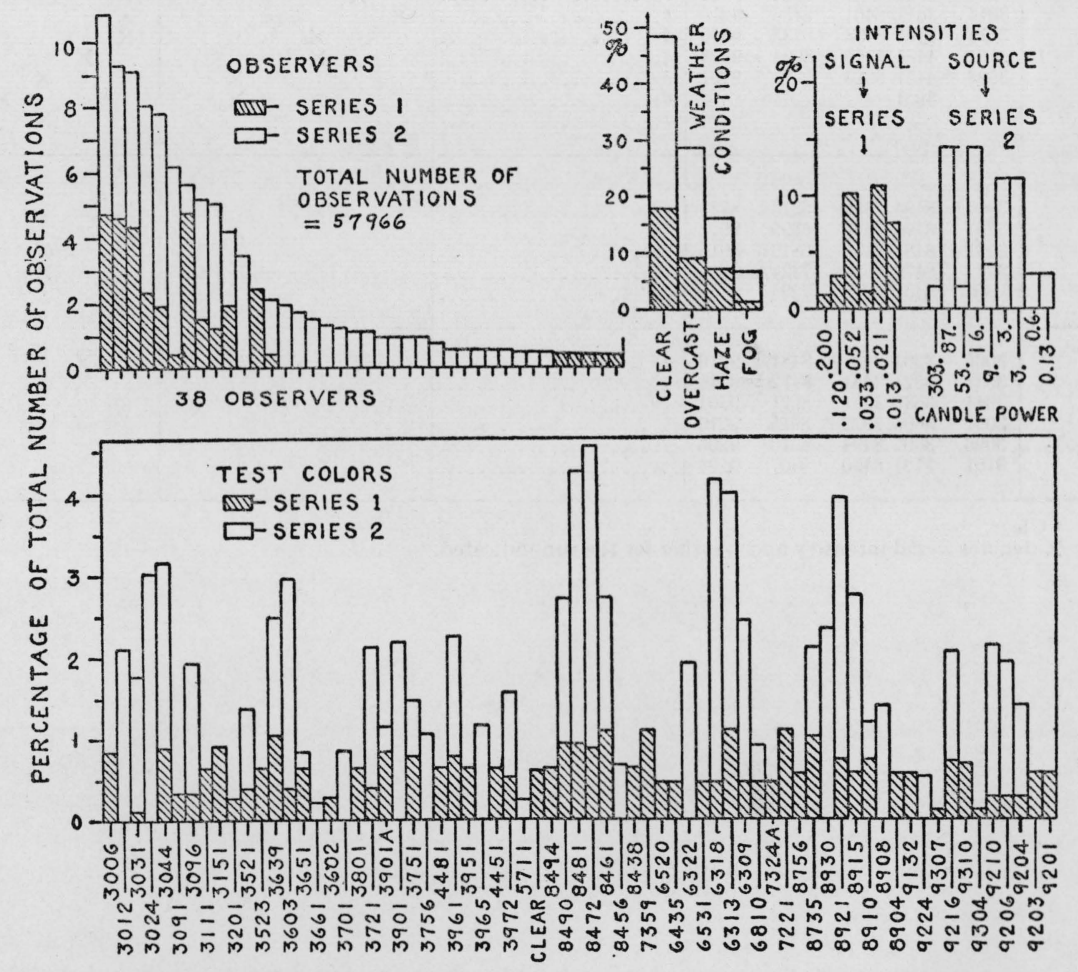

Frgure 5.-Distribution of field observations over the range of test colors, observers, weather conditions, and signal intensities covered in the present investigation.

In the selection of the two six-color sets with tolerance limits nearly 58,000 single color classifications were made by the 38 different observers. These observations are included in two series of test runs and are distributed among the different test colors, observers, signal or source intensities, and weather conditions, as depicted in the diagram of figure 5. Inasmuch as only a limited number of observations and range of test conditions could be included in one run with a given group of observers, both series of observations consisted of several runs which were made under varying conditions, as indicated in tables $3,4,5$, and 6 . 
TABLE 3.-Arrangement of field observations in series 1 , for different color sets, signal intensities, and weather conditions

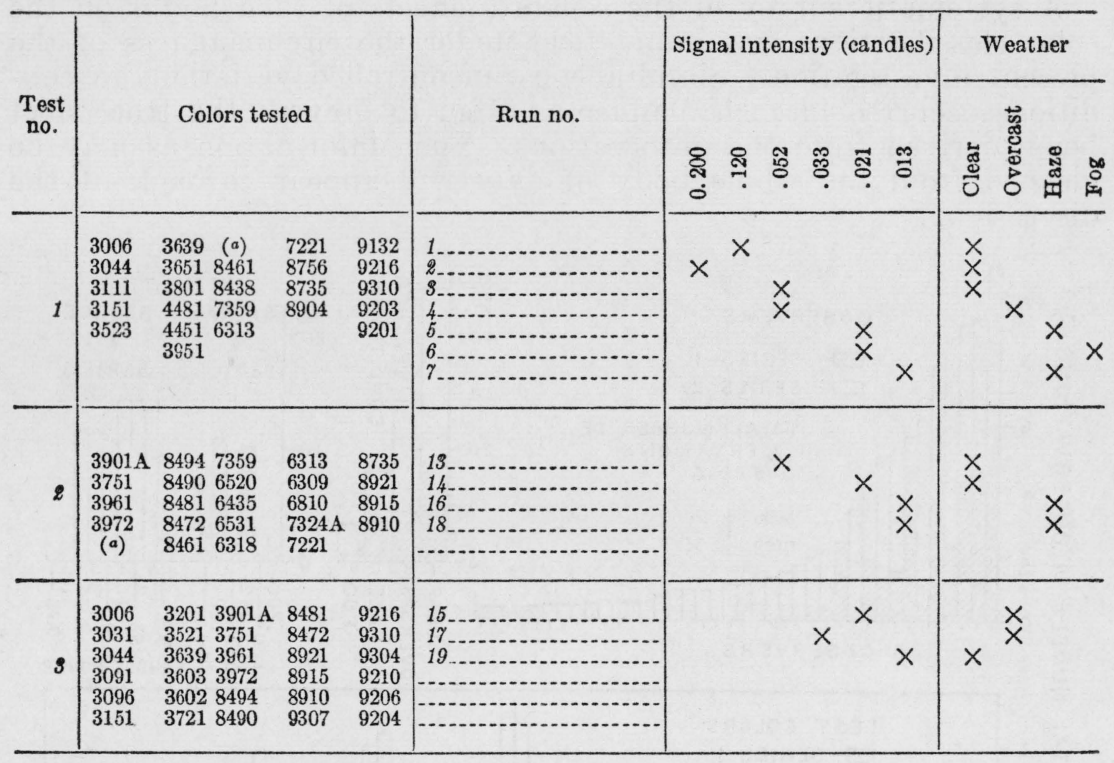

- Clear.

$x$ denotes signal intensity and weather for the run indicated. 
TABLE 4.-Arrangement of field observations in series 2 , for set $P$ colors, different source intensities, and weather conditions [ $X$ denotes colors, intensities, and weather for the run indicated. 0 denotes higher intensities used for blues and purples only]

\begin{tabular}{|c|c|c|c|c|c|c|c|c|c|}
\hline \multirow{3}{*}{ Run number } & \multicolumn{7}{|c|}{ Colors tested } & \multirow{2}{*}{$\begin{array}{l}\text { Source intensity } \\
\text { (candles) }\end{array}$} & \multirow{2}{*}{ Weather } \\
\hline & Red & Yellow & White & Green & Blue & & Purple & & \\
\hline & 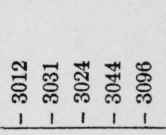 & 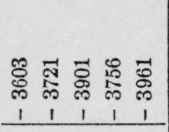 & 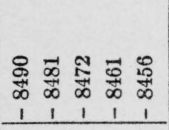 & 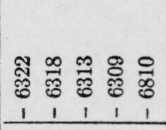 & \multicolumn{2}{|l|}{ 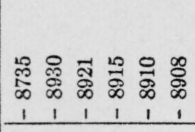 } & 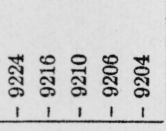 & 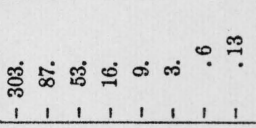 & 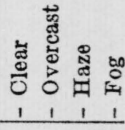 \\
\hline $\begin{array}{l}24 \\
27 \\
28 \\
30\end{array}$ & $\begin{array}{ll}\times \quad & \times \\
\times & \times \\
\times & \times \\
\times & \times \\
x\end{array}$ & $\begin{array}{l}x \\
\times \\
\times \\
\times \\
\times \\
\times\end{array}$ & $\begin{array}{l}x \times x \\
x \times x \\
x \times x \\
x \times x\end{array}$ & $\begin{array}{l}\times \underset{x}{\times} \quad x \\
\times \times \times \\
\times \times\end{array}$ & 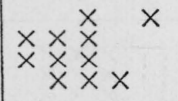 & & 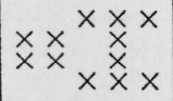 & $\begin{array}{r}\times \quad 0 \quad 0 \times \frac{x}{x} \\
0 \times 0 \times x\end{array}$ & $x_{x}^{x}$ \\
\hline \begin{tabular}{|c|c|}
31 & \\
34 &
\end{tabular} & $\begin{array}{l}\times \times \times \\
\times x \times x \\
x \times x\end{array}$ & 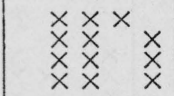 & 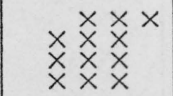 & 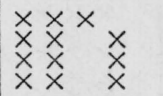 & $\begin{array}{ll}x \\
x \\
x & x \\
x\end{array}$ & $\begin{array}{l}\stackrel{x}{x} \\
\stackrel{x}{x} \\
\stackrel{x}{x}\end{array}$ & $\begin{array}{ll}x & x \\
x & \times \\
x & x \\
x & x \\
x & x\end{array}$ & 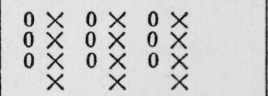 & $x^{x} x$ \\
\hline 41 45 & $\times \begin{array}{r}x \times x \\
\times x \\
\times x \\
\times x\end{array}$ & 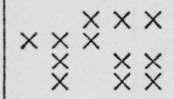 & 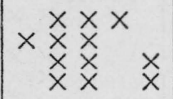 & $\begin{array}{l}\times \times \times \\
\times \times \times \\
\times \times \times \\
x \times\end{array}$ & $\begin{array}{l}x \underset{x}{x} \\
x \times \\
x \times\end{array}$ & $\begin{array}{l}\stackrel{x}{x} \\
\stackrel{x}{x}\end{array}$ & $\begin{array}{l}x \underset{\times}{x} \stackrel{x}{x} \times x \\
\times x\end{array}$ & 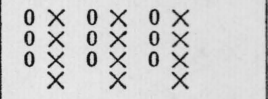 & $\stackrel{x}{x}$ \\
\hline
\end{tabular}


TABLE 5.-Arrangement of field observations in series 2, for set 0 colors, different source intensities, and weather conditions [ $X$ denotes the colors, intensities, and weather for the run indicated. 0 denotes higher intensities used for blues only]

\begin{tabular}{|c|c|c|c|c|c|c|c|c|}
\hline \multirow{3}{*}{ Run number } & \multicolumn{6}{|c|}{ Colors tested } & \multirow{2}{*}{$\begin{array}{l}\text { Source intensity } \\
\text { (candles) }\end{array}$} & \multirow{2}{*}{ Weather } \\
\hline & Red & Orange & Yellow & White & Green & Blue & & \\
\hline & 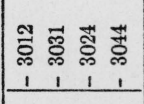 & 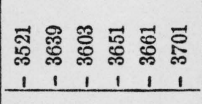 & 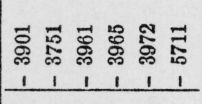 & 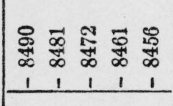 & 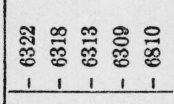 & 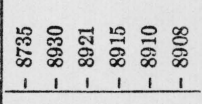 & 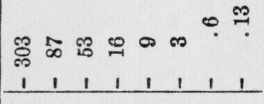 & 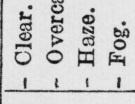 \\
\hline 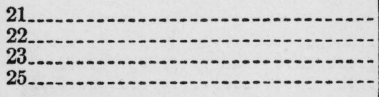 & $\stackrel{x}{x}_{x}^{x} x^{\stackrel{x}{x}}$ & $\begin{array}{l}x \times x \\
x \times x \\
x \times x \\
x \times x\end{array}$ & $\begin{array}{l}\times \times x \\
x \times x \\
x \times x\end{array}$ & $\begin{array}{l}x \times x \\
x \times x \\
x \times x \\
x \times x\end{array}$ & $\begin{array}{l}\stackrel{\times}{\times} \times \underset{\times}{\times} \times \underset{x}{\times} \\
\times \times \times\end{array}$ & $\begin{array}{rr}\stackrel{x}{x} & \stackrel{x}{x} \\
\times & \stackrel{x}{x}\end{array}$ & $\begin{array}{l}0 \stackrel{x}{x} \\
0 \stackrel{x}{x} \times \times\end{array}$ & $x^{x}$ \\
\hline 32 320 & 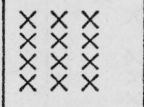 & $\begin{array}{ll}\times \underset{x}{x} \underset{x}{x} \\
\times \stackrel{x}{x} \\
x\end{array}$ & 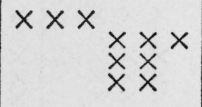 & $\begin{array}{l}x \underset{x}{x} \underset{x}{\times x} \times \underset{x}{x} \\
\quad \times x\end{array}$ & 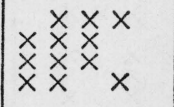 & 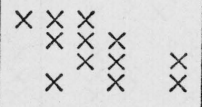 & $\begin{array}{lll}\stackrel{x}{x} & \stackrel{x}{x} & \stackrel{x}{x} \\
\stackrel{x}{x} & \stackrel{x}{x} & \stackrel{x}{x}\end{array}$ & $x_{x}^{x}$ \\
\hline 40. & $\begin{array}{l}x \times x \\
x \times x \\
x \times x \\
x \times\end{array}$ & $\begin{array}{r}\times \underset{x}{x} \times \stackrel{x}{x} \\
\times \underset{x}{x} \times\end{array}$ & $\times \times \times \begin{array}{l}\underset{x}{x} \\
x \times\end{array}$ & $\begin{array}{l}\stackrel{x}{x} \times \underset{x}{x} \times \underset{x}{x} \quad x\end{array}$ & 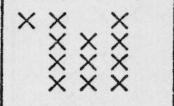 & $\begin{array}{l}x \underset{x}{x} \underset{x}{x} \\
x \times x\end{array}$ & $\begin{array}{lll}\stackrel{x}{x} & \stackrel{x}{x} & \stackrel{x}{x} \\
\stackrel{x}{x} & \stackrel{x}{x} & \underset{x}{x} \\
& x & \end{array}$ & $\begin{array}{l}x \\
x \\
x\end{array}$ \\
\hline
\end{tabular}


TABLE 6.-Signal intensities

\begin{tabular}{|c|c|c|c|c|c|c|c|c|c|}
\hline \multicolumn{9}{|c|}{ SERIES 2} & SERIES \\
\hline $\begin{array}{l}\text { Color } \\
\text { Avg. }{ }^{a} T_{\text {wo }}\end{array}$ & $\begin{array}{r}R \\
0.05\end{array}$ & $\begin{array}{c}O \\
0.32\end{array}$ & $\begin{array}{l}O-Y \\
0.48\end{array}$ & $\begin{array}{l}Y \\
0.63\end{array}$ & $\begin{array}{c}W \\
0.40\end{array}$ & $\begin{array}{c}G \\
0.07\end{array}$ & $\begin{array}{c}B \\
0.008\end{array}$ & $\begin{array}{c}P \\
0.004\end{array}$ & \multirow{2}{*}{$\begin{array}{c}\text { Signal } \\
\text { intensity } \\
\text { (candles) } \\
\text { for all } \\
\text { colors }\end{array}$} \\
\hline Source intensity (candles) & \multicolumn{8}{|c|}{$\begin{array}{l}\text { Signal intensity (candles) }=\text { source intensity } \times \text { avg } T_{w} \text {. Approxi- } \\
\text { mately } 79 \text { percent of all observations of series } 2 \text { were made at } \\
\text { source intensities of } 87,16 \text {, and } 3 \text { candles }\end{array}$} & \\
\hline & & & & & & & 2.4 & & \\
\hline $57-b$ & 4 & 28 & 42 & 55 & 35 & 6 & .7 & $\begin{array}{r}.3 \\
2\end{array}$ & $\cdots$ \\
\hline $\begin{array}{ll}16 \\
9\end{array}$ & .8 & 5 & 8 & 10 & 6 & 1 & $\begin{array}{l}.1 \\
.07\end{array}$ & $\begin{array}{l}.06 \\
.04\end{array}$ & $\begin{array}{r}0.20 \\
.12\end{array}$ \\
\hline B_-.. & .2 & 1.0 & 1.5 & 1.9 & 1.2 & .2 & .02 & .01 & .052 \\
\hline 130 & $\begin{array}{l}.03 \\
.006\end{array}$ & .22 & $\begin{array}{l}.3 \\
.06\end{array}$ & $\begin{array}{l}.4 \\
.08\end{array}$ & $\begin{array}{l}.2 \\
.05\end{array}$ & .04 & .005 & .002 & .021 \\
\hline
\end{tabular}

A verage luminous transmission of filters. See figure 4.

- Source intensities used only for blue and purple of set $P$.

- Source intensities used only in 1 run for each 6-color set.

The test colors of series 1 were selected to cover in small steps the entire range of chromaticities along the scale in figure 6 . The fulfilment of this condition depended, of course, on the availability of suitable colored-glass filters. The chief difficulty in this respect occurred throughout the blue-green region. However, such breaks as occur in the sequence of colors are in regions found to be unsuitable for the signal colors. In the classification of this series of colors the effect of color association is large, but it was desired to determine under this adverse condition the regions of maximum signal efficiency for all members of the two six-color sets. In the observations of series 2 these selected regions were reduced considerably and the limits adjusted to define the maximum acceptable tolerance ranges for members of each six-color set.

\section{CLASSIFICATION OF TEST COLORS, SERIES 1}

In test 1 , series 1 (table 3 ), the range of the purples, oranges, and yellows was covered in small steps, but only three representative colors were included in each of the red, white, green, and blue color classes. Observers were thus free to assign each test color to any one of the seven permitted classes. It was desired to indicate in this test the best value of $T_{\tau} / T_{w}$ for the purples and to select those colors which the observers as a group most consistently chose to identify as orange and yellow in distinction from red and white. In test 2 the colors were chosen with the specific purpose of determining the best green and the extent of this color region most suitable for use on equal terms with yellnw, white, and blue. In test 3 the colors were spaced to cover more uniformly all classes except the green, which was omitted only to reduce the total number of colors in the test. Some variation in observers and weather occurred in these tests, but in each run all signals appeared at the same intensity level, so that all signals had the same intensity advantage in the classification. The effect of the number of permitted color classes was apparent in these tests. Because of the absence of green in test 3 and the elimination of this 
possible classification it was found that the errors in the classification of the whites were thrown more to the blue in this test than they were in tests 1 or 2. The reverse effect was shown in the classification of the blues. Similarly, in test 2, the absence of red and orange caused the classification of the end yellows to be more perfect than they would have been had the orange and red classifications been permitted. In general, the colors called orange and yellow were less saturated in test 1 than in test 3 .

Taking these variations and all test conditions into consideration, a weighted average of all observations in series 1 was made, and adjusted so that the numbers representing different classifications of each color summed to 100 and defined the smooth continuous curves shown in the lower part of figure 6.

The following remarks are based on the results of this series of tests:

(1) Purples in the range between 9206 and 9204 contain the best proportion between red and blue. On the whole these purples are quite positively identified by all observers under the most adverse conditions of observation, provided the signal intensity is comparable with that of the other colors, as it was in this series of tests. Purples are, naturally, most often confused with red and blue. This is particularly the case for observers who do not completely resolve the blue and red components of purple and hence must discriminate between blue, purple, and red without full benefit of the aberration effect. Bluish purples are also slightly confused with white and green by a few observers.

(2) It is seen, conversely, that a strong blue (8904) or a strong red (3006) may be erroneously classified as purple, even though the blue signal contains no long-wave light and the red signal contains no shortwave light. Hence, a signal system including red, blue, and purple must limit the hue of the red and blue on the purple side and avoid low limits of signal intensity.

(3) A highly saturated "sextant" green (6318 to 6309) is required for maximum possible distinctiveness from a saturated blue or from white. The discrimination between white, green, and blue becomes unsatisfactory in passing from the sextant green to the blue-greens (7359 and 7221) of the type commonly employed in street and railroad signals. It is apparent that the saturated colors in the neighborhood of 6810 , 6318 , and 6309 must be employed in a signal system wherein blue enters on equal terms with green and white. The discrimination between green and white is good until the saturation of the green decreases to that of color 6435 , approximately.

(4) The orange and yellow are definitely the least distinctive colors of this seven-color set, showing the maximum confusion between one another and with the adjacent red and white. It is noted that the points of maximum confusion between orange and yellow and between red and white are both in the neighborhood of $600 \mathrm{~m} \mu$ on the wavelength scale, which is also the wave length found by Guild ${ }^{12}$ to represent the (homogeneous) spectrum color most efficiently discriminated from spectrum red and the "white" of a paraffin lamp. The dash-line curve in the figure is the sum of the ordinates for the orange and yellow and is drawn on the assumption that it would represent the field observations if only one color class had been permitted between

$12 \mathrm{~J}$. Guild, $\mathrm{On}$ the selection of a suitable yellow glass for railway signals, Proc. Int. Cong. Illum., Saranac Inn, N. Y., p. 862-887 (September 1928). 


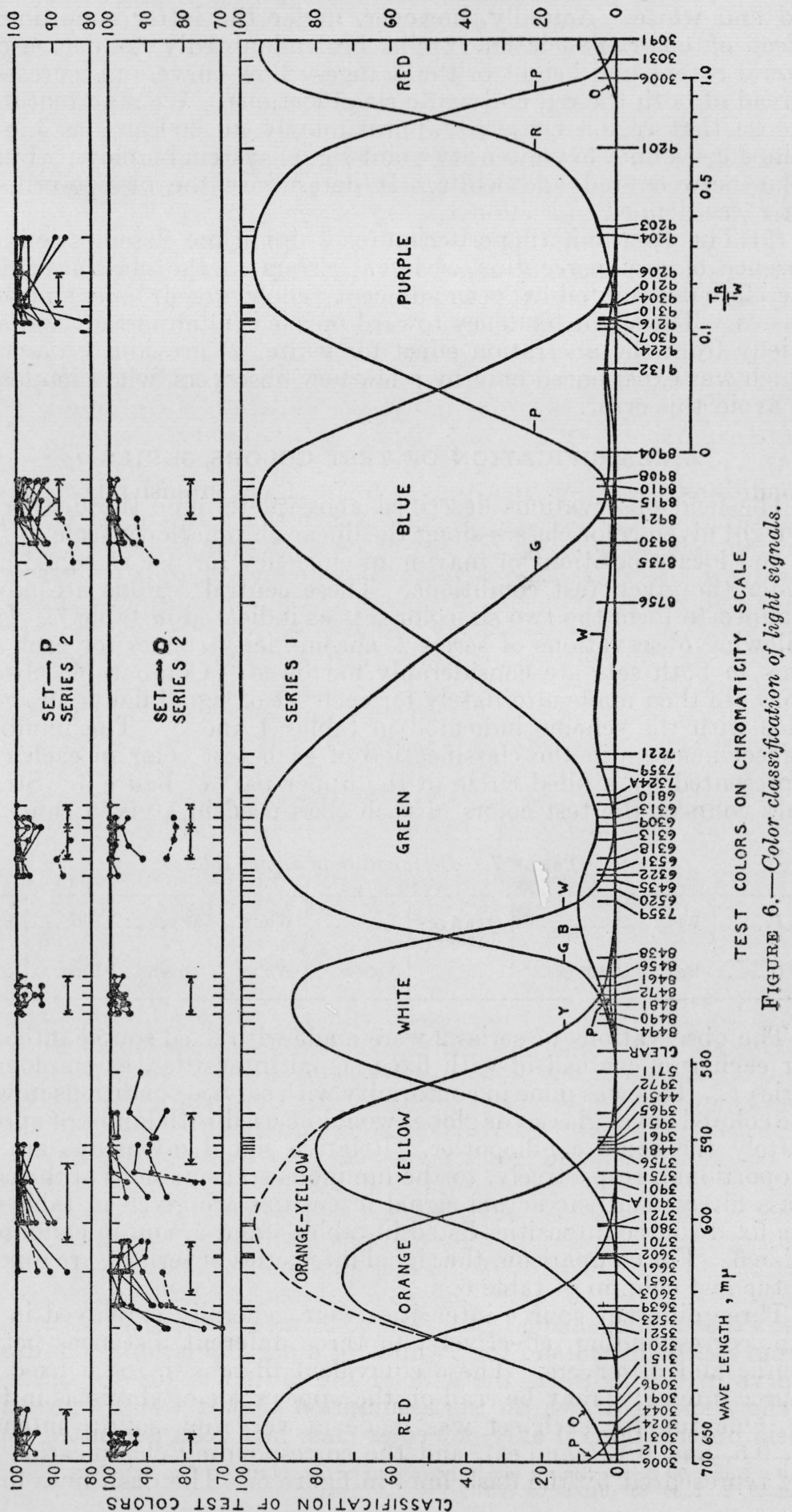


red and white. Actually, however, under the latter condition, the effect of color association would be undoubtedly to decrease the lateral extent and height of the orange-yellow curve and increase the spread of both the red and white classifications. We may tentatively choose that region centered approximately at $600 \mathrm{~m} \mu$ as the best color for use in a low-intensity point-signal system employing but one color between red and white. It determines the orange-yellow of set $P$, as defined in section $\mathrm{I}$.

(5) The discriminating criterion for white in the classification is the absence of any perception of hue. Errors in the classification are therefore distributed between adjacent yellow, green, blue, and purple classes. The slight tendency toward purple is unimportant and arises chiefly from the aberration effect for white, as previously described, which was experienced only by a few new observers, who soon learned to avoid this error.

\section{CLASSIFICATION OF TEST COLORS, SERIES 2}

The field observations described above determine the distribution of eight given color classes along the linear chromaticity scale in figure 6 , and locate positions of maximum efficiency for use as signal colors under the given test conditions. These central regions are now regrouped to form the two six-color sets as indicated in table 7. In the following observations of series 2, chromaticity ranges for each color class in both sets are considerably narrowed. Comparable observations are then made alternately for each set of signal lights, in accordance with the scheme indicated in tables 4 and 5 . The number of correct answers in the classification of each test color in each run is represented by a filled circle in the upper part of figure 6 . Straight lines connect the test colors of each class used in a given run.

TABLE 7.-Designation of signal colors

\begin{tabular}{|c|c|c|c|c|c|c|c|c|}
\hline Set $\boldsymbol{P}_{\text {. }}$ & Red... & - & Orange- & & White--. & Green & Blue.... & Purple. \\
\hline Set $\boldsymbol{O}$ & Red_-..... & Orange_-..- & 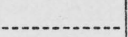 & Yellow_... & White.... & Green.... & Blue... & \\
\hline
\end{tabular}

The observations of series 2 were made with fixed source intensities for each run, instead of with fixed signal intensities, as employed in series 1 . This was done in conformity with service conditions in which the colored cover glasses or globes would be used with lamps of approximately the same candlepower. Relative signal intensities are then proportional, respectively, to the luminous transmissions of the coverglass filters; and the actual signal intensities are given in table 6 for the fixed source intensities listed in tables 4 and 5 , and in column 1 of table 6. For comparison, the signal intensities of series 1 are repeated in the last column of table 6 .

Three different source intensities were generally employed in each run, corresponding, effectively, to three different distances between source and observers. These equivalent distances, for a fixed 6-cp source intensity, may be read on the upper scale of abscissas in figure 9. One run for each set was made at very low source intensities ( $3,0.6$, and 0.13 cand'es), and the corresponding classification data are represented by the dash lines in figure 6 . The dash lines for the 
purple fell below the boundary of the diagram. Signal intensities were in this case well below the chromatic threshold of visibility for the majority of observers at 950 feet from the source. This was also the case to a lesser degree for some observers in the blue, green, and red. All data represented in figure 6 exclude such cases in which no color classification of the signals was possible because of low intensity.

It is seen that the reduction in the chromaticity range of the test colors for each class has markedly increased the distinctiveness of each signal. The effect of color association is greatly reduced. Again, as in series 1 , we find the orange and yellow of set $O$ to be the least distinctive of the signal colors, but the orange-yellow of set $P$ is quite satisfactory in this respect.

The observations of series 2 comprise 66 percent of the total and were made several months after series 1 was completed. Reference to figure 5 shows that the 11 out of 38 observers who participated in both series of tests also made 74 percent of all the observations. The range of signal intensities was greater in series 2 and very much higher throughout the orange, yellow, and white (table 6). A later analysis of the field observations (section $\mathrm{V}$ ) will show that the signals throughout the orange and yellow tend to shift toward the red at higher intensities. This intensity shift is manifested in figure 6 by a slight countershift to the white in the position of maximum distinctiveness for the orange, orange-yellow, and yellow of series 2 . Arrows in the figure (for series 2) indicate tolerance ranges adopted for the signal colors in each set. With due consideration for the intensity shift it is seen that both series of field tests are essentially in agreement with respect to the choice of the region of maximum efficiency for each signal color. A shift of the purple limits towards the blue was found to be feasible to gain the advantage of higher luminous transmission in the filters.

\section{EFFECT OF SIGNAL INTENSITY ON COLOR DISCRIMINATION}

The effects of varying weather conditions on the appearance and color classification of the signals is manifested chiefly through a corresponding variation in the absolute and spectral atmospheric absorption and scattering. In the present investigation no absorption or scattering measurements were made and only 7 percent of all field observations were recorded under weather conditions for which any marked selective effect would be expected on a test range of 950 feet. Under the most adverse weather conditions of the present field tests a greater spread in the classification of the signals was observed, but any change in the color classification which might be attributed to selective atmospheric absorption or scattering was small, if present at all, and could not be differentiated definitely from the more pronounced effects of the reduced signal intensity.

If a given test signal is assumed nominally to belong to a particular color classification, say orange, it is shown by the curves in the lower part of figure 6 that the classification by the group of observers is unequally distributed between the nominal and adjacent color classes. For present purposes some convenient parameter is required to indicate the shift in this color classification with changing signal intensity. Such an indication, for a given test color, is afforded by the percentage 
of unbalanced errors to the left, or to the right, of the nominal classification. The left and right sense is herein referred to corresponding directions along the chromaticity scale of figure 6 . Thus, a 100-percent shift to the left for color 3523 , which is nominally orange, would throw this color wholly into the red classification. The effect of signal intensity on the shift in color classification is represented graphically in figures 7 and 8 .

The most pronounced effect with increasing signal intensity is the general shift toward the red in the orange and yellow. The greater magnitude of the shift for the observations of series 1 (fig. 7) is consistent with the greater spread or uncertainty in the classification of these colors at a given intensity level. The spread or confusion in the classification actually increases from medium to highest signal intensities (fig. 8). It was observed by Guild, ${ }^{13}$ for a small source at
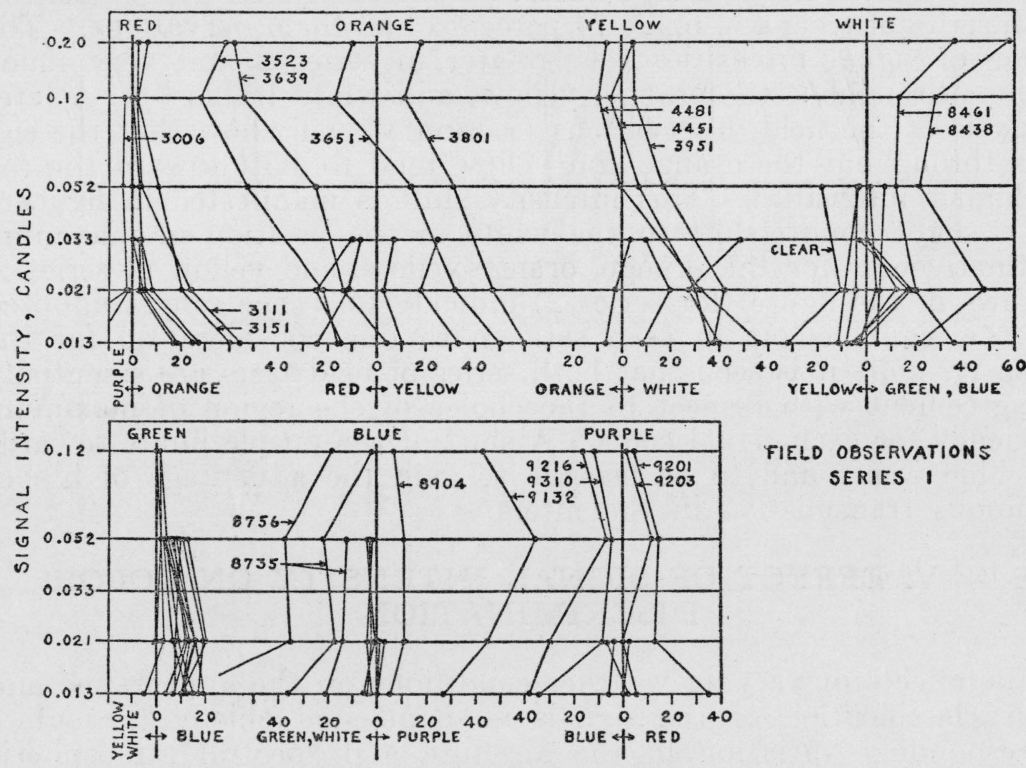

FIELD OBSERVATIONS SERIES 1

Frgure 7.-Effect of signal intensity on the color classification in series 1 .

1,200 feet, that the best (homogeneous) spectrum yellow for use between red and white also shifted away from red with increasing signal intensity. The present investigation is in substantial agreement with Guild in showing that whites are fairly stable over the range of intensities investigated with a slight tendency toward yellow at lowest intensities.

Another definite intensity effect is the shift of the saturated greens toward the blue for decreasing signal intensities. The less saturated green (6322) tends to shift toward the white and yellow. A reverse shift from the lighter blues toward green is indicated. Likewise, there is a shift of bluish purples toward blue and reddish purples toward red. A tendency is noted for reds to be classed as orange at the lowest and highest signal intensities.

${ }^{13} \mathrm{~J}$. Guild, On the selection of a suitable yellow glass for railway signals, Proc. Int. Cong. Illum., Saranac Inn, N. Y., pp. 862-887 (September 1928). 
In the observations of series 1 (fig. 7 and table 3 ) the variations in signal intensity occurred from one run to another and were accompanied by simultaneous variations in time, associated test colors, weather, and observers. In the observations of series 2 , on the other hand, the intensity effect is completely disentangled from any accompanying effects of other test conditions; for a given set of signals was always presented (singly) in each run at three different source intensities to the same group of observers under the same weather and other test conditions (fig. 8 , and tables 4 and 5).

\section{SELECTION OF SIGNAL COLORS AND TOLERANCES}

The range of permissible chromaticity variation for white is determined in each of the two six-color sets primarily by the absence of
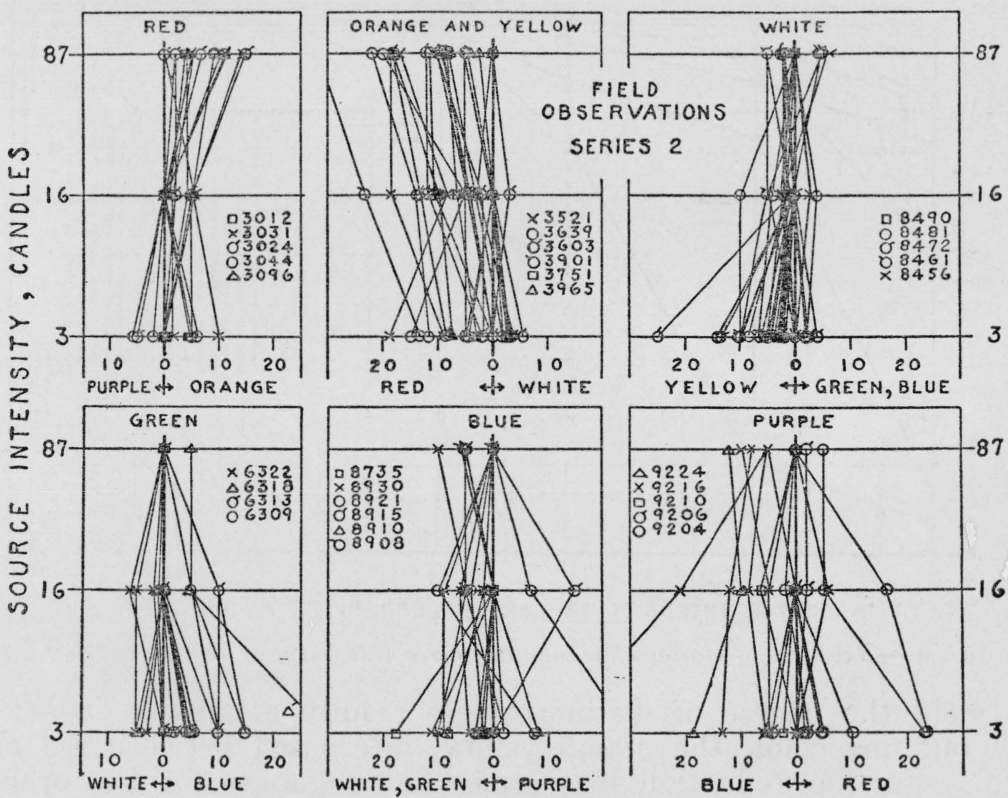

SHIFT IN COLOR CLASSIFICATION, PERCENT

Figure 8.-Effect of source intensity on the color classification in series 2.

any readily recognized hue by the group of normal observers. Having selected suitable limits for white on this subjective basis it is obvious that the limits for green and blue may be chosen the same likewise in both signal systems. The green (or light) limit for blue is selected for minimum confusion with green, and the tolerance permissible toward the stronger blue is determined by filter transmission and the condition that no excessive confusion with purple occurs in set $P$. These two objects are accomplished with one set of limits. Purple limits are chosen to minimize confusion with blue and red and yet gain as much as possible in filter transmission. Hence, in the observations of series 2 , the purple range was shifted as far as practicable toward the blue; that is, to lower values of $T_{r} / T_{w}$ (fig. 3). Likewise, to gain the maximum advantage in fi.ter transmission, red may be shifted farther toward the orange in set $P$ than in set $O$, but the purple 
(or dark) limit is again determined by confusion with purple and low filter transmission. The chromaticity tolerances to be permitted in practice must be decided also in relation to manufacturing problems for the colored glassware, and minimum ranges employed in the tests of series 2 were chosen with due consideration to such restrictions. The choice was guided in this respect by the experience of manufacturers in the supply of signal glass for American railroads.

It has been shown that the orange and yellow of set $O$ are the least. distinctive of all the signal colors. The discrimination between red, orange, yellow and white might be improved somewhat by further reducing the permissible tolerances in the orange and yellow; but this would markedly increase the cost of the glassware and would then

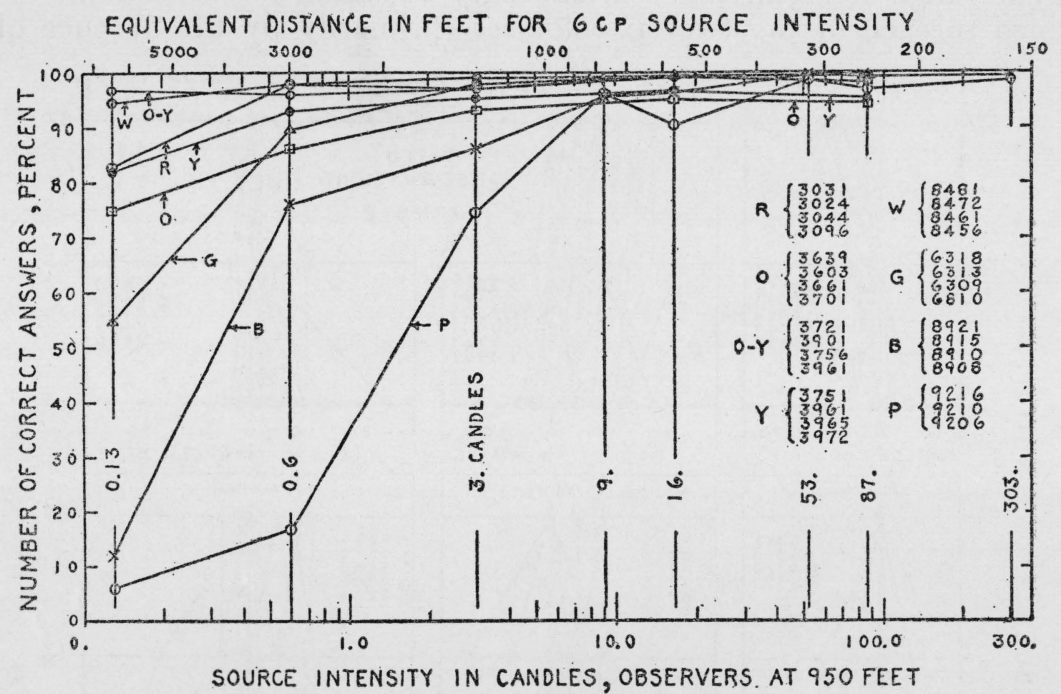

FIGURE 9.-Relation of signal efficiency to source intensity, or equivalent distance.

not yield the degree of distinctiveness readily attainable in set $P$ with but one color, the orange-yellow, interposed between red and white. Further reduction in permissible tolerances for the orange and yellow is also limited effectively by observer variations and the intensity effect. The variation between observers within the group is greatest in this chromaticity region; the individual's criterion for the classification is less stable. Narrow limits chosen for low signal intensities would require an appreciable shift toward the white at high intensities - for the same signal efficiency. Thus, no real advantage may be expected from further reduction in the chromaticity tolerances for orange and yellow. The range of the orange-yellow in set $P$ may be made sufficiently broad to meet all practical requirements and yet maintain a satisfactory signal efficiency for the group of observers over the required intensity (or distance) range. It may be noted also, as shown in figure 9, that the signal efficiency of the orange and yellow does not improve for the higher signal intensities, so that an identification error made under actual service conditions would not be corrected necessarily by a closer approach to the signal light. 
On the whole, these considerations all lead to the elimination of orange and the final choice of the set $P$ colors as yielding the six-color system of highest efficiency under the prescribed service conditions. The source intensity for the purple signal must be sufficient, however, to gain the required distance range. The limits selected for the orange-yellow are based on the assumption that a low source intensity will be used so that the signal intensity is roughly comparable with the other signals in this respect, in accordance with the field tests of series 1 . They should be shifted slightly to the right if the signal intensities of series 2 prevail in practice.

The limits selected for each signal on the special chromaticity scale are listed in table 8. The minimum source intensity for each signal light, for efficient color identification over the 950 -foot range, is estimated from the data in figure 9 and also recorded in table 8. In the last column of this table these source intensities are reduced to equivalent signal intensities for a 1,500-foot range, using the average transmission values from figure 4 and the inverse-square law of photometry.

TABLE 8.-Chromaticity tolerances and minimum signal intensities recommended for signal colors

\begin{tabular}{|c|c|c|c|c|c|c|c|c|c|}
\hline \multirow{3}{*}{ Signal color } & \multirow{3}{*}{$\begin{array}{l}\text { Designation } \\
\text { of limits }\end{array}$} & \multicolumn{6}{|c|}{ Trilinear coordinates } & \multicolumn{2}{|c|}{ Minimum intensity } \\
\hline & & \multicolumn{3}{|c|}{ UCS system (Judd) } & \multicolumn{3}{|c|}{ ICI system (standard) } & \multirow{2}{*}{$\begin{array}{l}\text { Source } \\
\text { for } \\
950-\mathrm{ft} \\
\text { range } \\
\text { (candies) }\end{array}$} & \multirow{2}{*}{$\begin{array}{l}\text { Signal } \\
\text { for } \\
1,500-\mathrm{ft} \\
\text { range } \\
\text { (candles) }\end{array}$} \\
\hline & & $r$ & $g$ & $b$ & $x$ & $y$ & $z$ & & \\
\hline Red... & $\left\{\begin{array}{l}\text { Purple............ } \\
\text { Orange }\end{array}\right.$ & $\begin{array}{l}0.993 \\
0.944\end{array}$ & $\begin{array}{r}0.007 \\
.056\end{array}$ & $\begin{array}{r}0.000 \\
.000\end{array}$ & $\begin{array}{r}0.733 \\
.716\end{array}$ & $\begin{array}{r}0.267 \\
.284\end{array}$ & $\begin{array}{r}0.000 \\
.000\end{array}$ & 3. & 0.4 \\
\hline Orange-yellow & $\left\{\begin{array}{l}\text { Red } \\
\text { White }\end{array}\right.$ & $\begin{array}{l}.766 \\
.680\end{array}$ & $\begin{array}{l}.234 \\
.320\end{array}$ & $\begin{array}{l}.000 \\
.000\end{array}$ & $\begin{array}{l}.641 \\
.593\end{array}$ & $\begin{array}{l}.359 \\
.407\end{array}$ & $\begin{array}{l}.000 \\
.000\end{array}$ & 1. & 1.2 \\
\hline White.. & $\left\{\begin{array}{l}\text { Yellow } \\
\text { Blue }\end{array}\right.$ & $\begin{array}{l}.497 \\
.455\end{array}$ & $\begin{array}{l}.450 \\
.467\end{array}$ & $\begin{array}{l}.053 \\
.078\end{array}$ & $\begin{array}{l}.388 \\
.333\end{array}$ & $\begin{array}{l}.383 \\
.347\end{array}$ & $\begin{array}{l}.229 \\
.320\end{array}$ & 1. & 1.0 \\
\hline Green. & $\left\{\begin{array}{l}\text { Yellow } \\
\text { Blue............... }\end{array}\right.$ & $\begin{array}{l}.380 \\
.343\end{array}$ & $\begin{array}{l}.605 \\
.608\end{array}$ & .015 & $\begin{array}{l}.274 \\
.212\end{array}$ & $\begin{array}{l}.626 \\
.516\end{array}$ & $\begin{array}{l}.100 \\
.272\end{array}$ & 3. & .6 \\
\hline Blue.. & $\left\{\begin{array}{l}\text { Green } \\
\text { Purple............ }\end{array}\right.$ & $\begin{array}{l}.233 \\
.229\end{array}$ & $\begin{array}{l}.386 \\
.345\end{array}$ & $\begin{array}{l}.381 \\
.426\end{array}$ & $\begin{array}{l}.146 \\
.150\end{array}$ & $\begin{array}{l}.055 \\
.032\end{array}$ & $\begin{array}{l}.799 \\
.818\end{array}$ & 15. & .3 \\
\hline Purple.. & $\left\{\begin{array}{l}\text { Blue } \\
\text { Red................ }\end{array}\right.$ & $\begin{array}{l}.270 \\
.276\end{array}$ & $\begin{array}{l}.344 \\
.317\end{array}$ & $\begin{array}{r}.386 \\
.407\end{array}$ & $\begin{array}{r}.169 \\
.173\end{array}$ & $\begin{array}{l}.049 \\
.038\end{array}$ & $\begin{array}{r}.782 \\
.789\end{array}$ & 21. & .2 \\
\hline
\end{tabular}

It is evident that the experimental results of the present investigation do not define complete boundaries of regions on the color diagram of figure 2 , within which a two-dimensional chromaticity variation is permissible for each signal color. In particular, considerable latitude in this respect is permissible in the establishment of such boundaries for the green. Only the intersections of such regions with the special linear chromaticity scale are roughly indicated in the present paper. Thus, only one yellow and one blue limit is suggested for the green. The lowest practical transmission for the filter used will determine the high saturation limits for this region, which is consistent with the maintenance of suitable signal intensities. All other signal colors of the system may be limited, by practical considerations in the choice of filters, to narrow strips centered along the linear chromaticity scale. 
It is beyond the scope of the present paper to set up complete definitions for such chromaticity regions. The exact definitions, when incorporated in master specifications, will involve the choice of some particular coordinate system and simple analytical descriptions of the boundaries. These boundaries also may be adjusted to some degree to accommodate the colorimetric properties of such colored glassware most readily obtainable from manufacturers. Work is in progress on the formulation of such master specifications and simplified working specifications in terms of specific physical properties of the source and glassware. ${ }^{14}$

Washington, August 21, 1936.

14 Such master specifications and simplified working specifications for the signal colors and glasses used on American railroads have already been formulated and are incorporated in AAR (Association of American Railroads) Signal Section specification 69-35, officially approved and issued by the AAR in Dec. 1935 The National Bureau of Standards cooperated in this investigation with the A A R Signal Section and with Corning Glass Works. The Bureau's work leading up to this specification is described in a series of reports by K. S. Gibson and Geraldine K. Walker, published in Signal Section proceedings, Am. Railway Association, 30, no. 2, 441 (1933). Requests for copies of specification 69-35 and the Proceedings should be addressed to R. H. C. Balliet, Secretary, AAR Signal Section, 30 Vesey Street, Now York, N. Y. 